\title{
Isolation and Molecular Identification of Yeasts in Different Food Stuff and Determine Their Abilities for Phenols and Flavonoids Productivity by HPLC Analysis
}

\author{
Eman Mostafa Mohamed, Maysa Ahmed, Somaya Nassar* \\ Department of Botany \& Microbiology, Faculty of Science, Assiut University, Assiut, Egypt \\ Email address: \\ s.m.nassarmicro@gmail.com (S. Nassar) \\ ${ }^{*}$ Corresponding author \\ To cite this article: \\ Eman Mostafa Mohamed, Maysa Ahmed, Somaya Nassar. Isolation and Molecular Identification of Yeasts in Different Food Stuff and \\ Determine Their Abilities for Phenols and Flavonoids Productivity by HPLC Analysis. International Journal of Ecotoxicology and \\ Ecobiology. Vol. 4, No. 3, 2019, pp. 71-79. doi: 10.11648/j.ijee.20190403.13
}

Received: August 28, 2019; Accepted: September 23, 2019; Published: October 9, 2019

\begin{abstract}
This investigation was isolated forty-three spoilage yeasts from twelve different spoilage food sources included (guava, tomato, strawberry, pickled carrot, orange juice, grape, date, cheese, potato, okra, onion and dough) by used three kinds of media (PDA, MYEA and MEA) and three isolation techniques (touch, direct and dilution plate methods). The result recorded that the guava represent the richest sources with 15 yeasts isolated. The MYEA medium represented the most suitable medium for isolation of yeast from these sources and recorded 35 yeasts isolates, and also the result show that 28 yeasts isolates were isolated by direct plate method which represented the most suitable techniques for yeast isolation from the previous sources. The isolated yeast was classified according to their colony colors into four categories includes white, offwhite, creamy and red colors. The total numbers of isolated yeast and its kinds are affected by the source, techniques, and media used in isolations. The ability of all isolated yeasts was screened for phenol and flavonoid productivity. The highest productive phenol and flavonoid yeasts were selected for identifying by molecular techniques, performed by phenotypic characteristics and ITS region. Also, those highest phenols and flavonoid producers strains were confirmed their productivity by using HPLC analysis.
\end{abstract}

Keywords: Yeast, Isolation, Molecular Identification, Phenol, Flavonoid, HPLC

\section{Introduction}

Yeast has a wide range of distribution in nature. Numerous references recorded that yeast has a wide range of biodiversity and distributed in everywhere and habitats. It isolated and recovered from aquatic, marine, atmospheric, terrestrial habitats, fruits and vegetables at low $\mathrm{pH}$ levels and selective techniques are often used for recovery of yeasts $[1$, 2, 3-5].

Yeast genus and species are identified morphological, physiological, biochemical activity, genetically, and immunological. DNA sequence analysis results are easy and speed of identification, making intense biodiversity surveys and almost manageable [3, 6, 7-10].

Since ancient civilizations back to 5,000 years ago yeast were used in the preparation of bread and alcoholic beverage.
It produced numerous bioactive metabolites which have wide applications and uses in traditional folk and modern medicine, cookery, food industry and fermented foods "beverage, meat products, dairy products, bread and packing, juice, tea, jam, and sweets." Bioactive metabolites produced from yeast are used in the medicinal and pharmaceutical industry for human hormone, hepatitis B vaccine, insulin, $\alpha$ interferon, and tissue plasminogen activator, for lysis of blood clots products. Recently yeast genetic engineering used in the agricultural production of crops.

Phenols and flavonoids are natural secondary metabolites derived from two metabolic pathways include Shikimic acid (aromatic amino acids) and Acetyl-Coenzyme A pathways. Over 9,000 compounds of this group are known. Phenols have a wide distribution in many microorganisms recorded by many authors [11-14]. 
Natural phenols and flavonoids inside the living cells are classified into free phenols found in the vacuoles of the plant cells, conjugated phenols and structural or bound phenol in cell wall through several covalent bonds. Free phenols compounds can be effectively extracted by conventional techniques, while several hydrolysis processes have been used to enhance the release of bounded phenols. The best processes to obtain extracts with high-quality, high activity and using environmentally friendly techniques is fermentation. Extraction of phenols and flavonoids from plants occurs by several methods including physical, physiochemical, and chemical techniques such as organic solvent, ultrasound-assisted, microwave-assisted, a cold pressing, and a supercritical fluid. These techniques can't release the cell walls bound phenols and have a low yield. Microbial fermentation by bacteria, yeast and fungi processes release phenols from plant substrate are more effective and gives a high yield [14-18].

This investigation has been designed for study the following aims such as isolation of yeasts from different foods sources, cultivation of yeasts samples for obtained their metabolites by methanolic extraction for studying their antibacterial activities and make screening for testing yeast productivity of phenols and flavonoids as a natural active antioxidant metabolite by using many analytical methods. Select the highest yeast phenols and flavonoids producers yeasts for identification by molecular technique, also confirmed their ability to the production of phenols and flavonoids by HPLC analysis.

\section{Materials and Methods}

\subsection{Yeast Isolation from Different Food Sources}

\subsubsection{Collection of Food Samples}

A hundred grams from different foodborne yeast samples were collected from different places at Assiut governorate included fruits and its products (grape, guava, dates, and orange juice); vegetables (tomato, strawberry, onion, and carrot); others food (cheese, okra, potato, and dough). The samples were placed in a double sterile polyethylene bag (to minimize the loss of water content and provide ancient aeration), sealed, transferred immediately to the laboratory, kept in a cool place at $5^{\circ} \mathrm{C}[3,19,20]$.

\subsubsection{Yeast Isolation Media}

Three kinds of media were employed for isolation of yeast includes Yeast Malt Extract Medium (MYE), Malt Extract Medium (MEA), Potato Dextrose Agar Medium (PDA) [3, 19, 20].

\subsubsection{Yeast Isolation Techniques}

Yeasts were isolated from different sources by three techniques included: Dilution plate method, Direct touch method and Direct plate method. In each method, the plates were incubated at $25-28^{\circ} \mathrm{C}$ for $48-72$ hours. The yeast colonies are counted, recorded their color, isolated and purified $[3,7,19-22]$.

\subsection{Yeast Inoculums and Cultivation}

Malt Yeast Extract broth medium (MYE) was prepared and used for the preparation of yeast inoculum. The medium was adjusted to $\mathrm{pH} 3.7$ and autoclaved at $121^{\circ} \mathrm{C}$ for $20 \mathrm{~min}$. A loop full of yeast inoculum was taken from a pure culture of the yeast isolate and inoculated into $50 \mathrm{~mL}$ of the sterilized medium then incubated for 72 hours at $28^{\circ} \mathrm{C}$ on a shaker (Environ-Shaker 3597-1) at $100 \mathrm{rpm}$. Each broth culture was centrifuged (CRU-5000 Centrifuge IEC) for $15 \mathrm{~min}$ at 5000 rpm. At Botany and Microbiology Department, Faculty of Science, Assiut University [23].

\subsection{Preparation of Yeast Methanolic Extract(s)}

The cell biomass was dried, weighted, and homogenized with $40 \mathrm{ml}$ methanol in a high-speed blender at $16.000 \mathrm{rpm}$. The homogenized mixture was kept in a shaker overnight. The mixture was filtered through Whitman filter paper No. 2 and dried over anhydrous $\mathrm{Na}_{2} \mathrm{SO}_{4}$. The extract was concentrated and dried. These media were autoclaved at $121^{\circ} \mathrm{C}$ for 20 minutes, cooled to approximately $45^{\circ} \mathrm{C}$ and adjusted to $\mathrm{pH} 3.7$ [3, 19-27].

\subsection{HPLC Analysis for Screening of Yeast Phenols and Flavonoids as Active Metabolites}

Screening of the phenols and flavonoids productivity as yeast natural active metabolites in methanolic extracts were tested by used many analytical methods and Spectrophotometric analysis according to and includes:Sodium hydroxide $(\mathrm{NaOH})$, Thin Layer Chromatographic Analysis (TLC), $\mathrm{ALCl}_{3}$, Folin-Ciocalteau's reagent.

Five highest phenols and flavonoids producers yeast recorded by the different analytical methods and selected for confirmed their productivity by HPLC analysis. The yeast methanolic extracts were tested and performed by Agilent HPLC analysis, model 6890 N/5975B (Agilent Technologies, Palo Alto, CA, USA) at the analytical Chemistry Unit, ACAL, Chemistry Department, Faculty of Science, Assiut University, Assiut, Egypt [28-34, 35, 36].

\subsection{Yeast Identification by Genotypic Characterization}

Recently yeast identification by genotypic characterization was more accurate and used on large scale around the world. The most significant ten yeasts in physiological studies were selected and identified by a molecular technique in international Korean Lab. Yeast was grown on Sabouraud's dextrose agar (SDA) plates and incubated at $25^{\circ} \mathrm{C}$ for 7 days. A small amount of yeast growth was scraped and suspended in $200 \mu \mathrm{l}$ of distilled water and boiled at $100^{\circ} \mathrm{C}$ for 15 minutes and stored at $-70^{\circ} \mathrm{C}$, and sent to Sol Gent Company, South Korea. Yeast DNA was extracted and isolated using Sol Gent purification bead in Sol Gent Company (Daejeon, South Korea). Internal transcribed spacer (ITS) sequences of nuclear ribosomal DNA were amplified using primers ITS1, ITS4 as follow: universal primer ITS 1 (5'-TCC GTA GGT GAA CCT GCGG-3'), and ITS 4 (5'-TCC TCC GCT TAT 
TGA TAT GC-3'). Contigs were created from the sequence data using CLC Bio Main Workbench program. The sequence obtained from each isolate was further analyzed using BLAST from the National Center of Biotechnology Information (NCBI) website. Sequences obtained with those retrieved from Gen Bank database were subjected to Clustal $\mathrm{W}$ analysis using Meg Align (DNA Star) software version 5.05 for the phylogenetic analysis. Sequence data were deposited in Gen Bank and accession numbers are given for them. The identified yeast strains are deposited in Assiut University Moubasher Mycological Center (AUMMC) [37].

\section{Results and Discussion}

\subsection{Yeast Isolation}

\subsubsection{Effect of Different Isolation Sources}

The total numbers of isolated yeast are varying depending upon the isolation sources. Fifteen isolates (represent $35 \%$ of total isolates) isolated from guava followed by tomato 11 isolates (represent $26 \%$ of total isolates), three isolates (represent $7 \%$ of total isolates) were isolated from each of (pickled carrot, straw berry, and orange), two isolates (represent $5 \%$ of total isolates) were isolated from grape and one isolate was isolated from each of date, cheese, okra, potato, dough and onion Table 1 \& Figure 1.

\subsubsection{Effect of Different Isolation Media}

Three types of media were used for isolation. The isolated number of yeasts from each source is varying with using a different type of media. Six isolates were isolated from guava by using MEA medium, but in case of using MYEA medium for isolation (9 isolates) were isolated and in case of using PDA for isolation no isolate was recovered. Isolation from tomato using MYE medium resulted in (10 isolates), but in case of using PDA medium for isolation (1 isolates) was obtained and no isolates in case of using MEA medium for isolation. MYE medium was the most suitable media for isolation from these sources Table $1 \&$ Figure 2.

\subsubsection{Effect of Different Isolation Techniques}

Three types of isolation techniques were used for isolation yeast from each source and the result showing that the isolated number of yeasts from each source varying with using different isolation technique. The total yeast isolates recorded in case of using the direct dilution method recorded 28 isolates, the touch method recorded 8 isolates and dilution plate method recorded 6 isolates Table $1 \&$ Figure 3.

\subsubsection{Variation of Colony Color of Isolated Yeasts}

The isolated yeast could be classified into four categories depending on their variation in colony color: white (21 isolates), creamy white (12 isolates), off white (9 isolates) and red ( 1 isolate) as showed in Table $1 \&$ Figure 4.

Table 1. Summarized the result of 43 spoilage yeasts from 12 food sources includes by used 3 kinds of media and 3 isolation techniques

\begin{tabular}{|c|c|c|c|c|c|c|c|}
\hline \multirow{2}{*}{$\begin{array}{l}\text { Food isolation sources of yeasts } \\
\text { Scientific names }\end{array}$} & \multirow[b]{2}{*}{ Common names } & \multicolumn{5}{|c|}{ Yeast colony color categories } & \multirow[b]{2}{*}{ Total No. } \\
\hline & & $\%$ & White & Creamy & Off-white & Red & \\
\hline Psidium guajava $\mathrm{L}$. & Guava & 35 & 12 & 2 & 1 & - & 15 \\
\hline Solanum lycopersicum L. & Tomato & 26 & 7 & 1 & 3 & - & 11 \\
\hline Fragaria ananassa Duchesne & Strawberry & 7 & - & 3 & - & - & 3 \\
\hline Daucuscarota (Hoffm) Schübl \& Martens & Pickled carrot & 7 & - & 1 & 1 & 1 & 3 \\
\hline Citrus sinensis L. & Orange & 7 & 1 & 1 & 1 & - & 3 \\
\hline Vitis vinifera $\mathrm{L}$. & Grape & 5 & - & 1 & 1 & - & 2 \\
\hline Cheese & & 2 & - & - & 1 & - & 1 \\
\hline Solanum tuberosum L. & Potato & 2 & - & 1 & - & - & 1 \\
\hline Abelmoschuse sculentus (L.) Moench & Okra & 2 & - & 1 & - & - & 1 \\
\hline Allium cepa L. (Onion) & & 2 & - & - & 1 & - & 1 \\
\hline Dough & & 2 & - & 1 & - & - & 1 \\
\hline Twelve isolation sources & & 100 & 21 & 12 & 9 & 1 & 43 \\
\hline
\end{tabular}

Table 1. Continued.

\begin{tabular}{|c|c|c|c|c|c|c|c|}
\hline \multicolumn{2}{|l|}{ Food isolation sources of yeasts } & \multicolumn{3}{|c|}{ Isolation media } & \multicolumn{3}{|c|}{ Isolation techniques } \\
\hline Scientific names & Common names & MEA & MYEA & PDA & Touch & Direct PM & Dilution PM \\
\hline Psidium guajava $\mathrm{L}$. & Guava & 6 & 9 & - & 5 & 10 & - \\
\hline Solanum lycopersicum L. & Tomato & - & 10 & 1 & 2 & 6 & 3 \\
\hline Fragaria ananassa Duchesne & Strawberry & - & 3 & - & - & 3 & - \\
\hline Daucuscarota (Hoffm) Schübl \& Martens & Pickled carrot & - & 3 & - & - & 3 & - \\
\hline Citrus sinensis $\mathrm{L}$. & Orange & - & 3 & - & - & - & 3 \\
\hline Vitis vinifera L. & Grape & - & 2 & - & 1 & 1 & - \\
\hline Cheese & & - & 1 & - & - & 1 & - \\
\hline Solanum tuberosum L. & Potato & - & 1 & - & - & 1 & - \\
\hline Abelmoschuse sculentus (L.) Moench & Okra & - & - & 1 & - & 1 & - \\
\hline Allium cepa L. (Onion) & & - & 1 & - & - & 1 & - \\
\hline Dough & & - & 1 & - & - & - & 1 \\
\hline Twelve isolation sources & & 6 & 35 & 2 & 8 & 28 & 7 \\
\hline
\end{tabular}




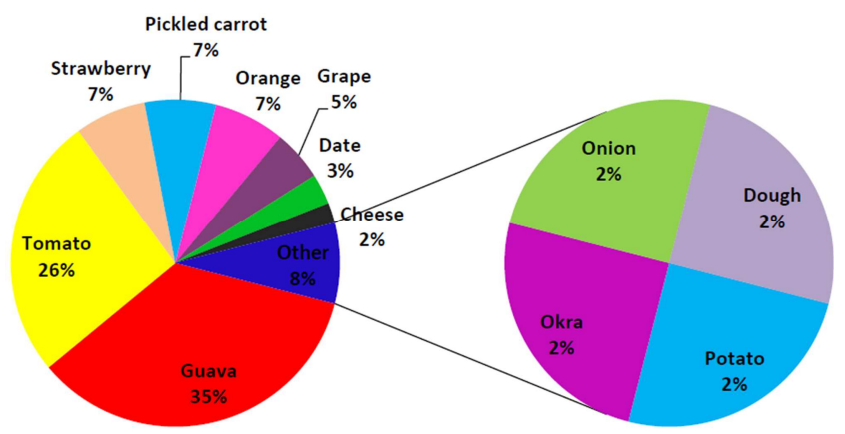

Figure 1. Percentage of isolated yeasts from different sources.

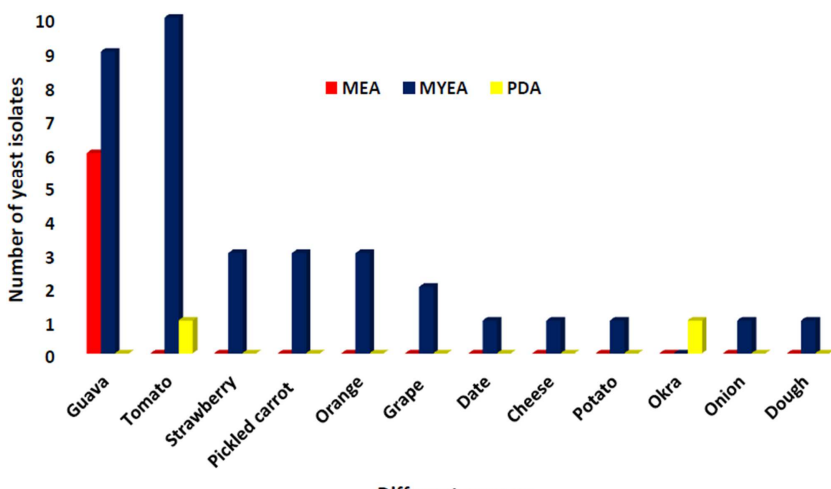

Diffrenet sources

Figure 2. Yeast isolation using different types of media.

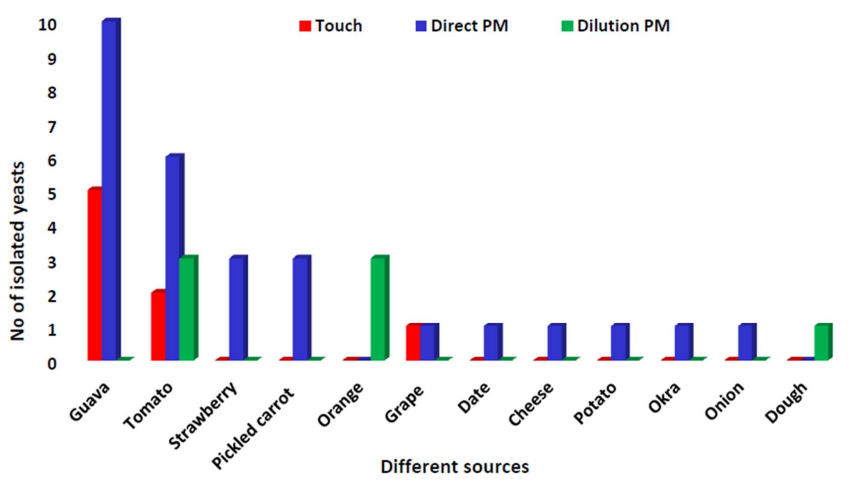

Figure 3. Isolation of yeast using different techniques.

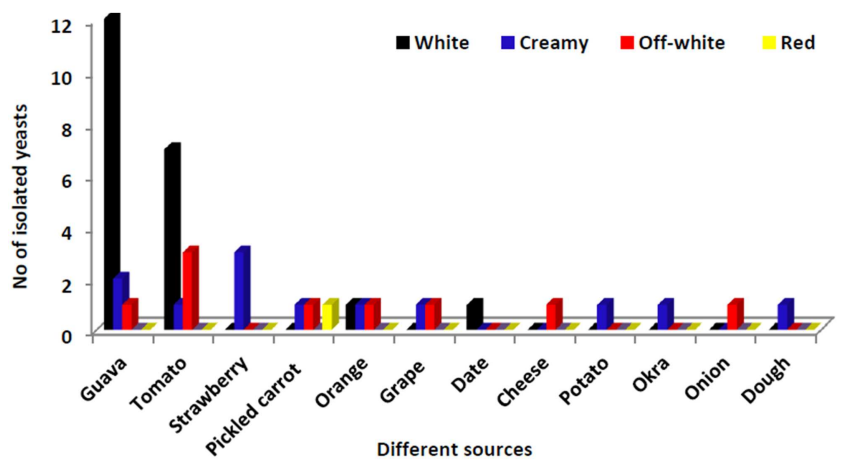

Figure 4. Variation in colony color of isolated yeast.

Table 2. Hplc analysis for conformation of the yeast ability to produce phenols and flavonoids as an active metabolites.

\begin{tabular}{|c|c|c|c|c|c|c|c|c|c|}
\hline \multirow{4}{*}{$\begin{array}{l}\text { Strain Name No. of Gene } \\
\text { bank (AUMC) }\end{array}$} & \multirow{2}{*}{\multicolumn{3}{|c|}{$\begin{array}{l}\text { A simple test with a yellow color } \\
\text { appearance }\end{array}$}} & \multicolumn{2}{|c|}{ Spectrophotometric reading } & \multirow{2}{*}{\multicolumn{3}{|c|}{ HPLC mg /L }} & \multirow{4}{*}{$\begin{array}{l}\text { Antibacter } \\
\text { ial activity }\end{array}$} \\
\hline & & & & \multirow{3}{*}{\begin{tabular}{|l|} 
At 765nm \\
Folin (Blue) \\
Phenol \\
\end{tabular}} & \multirow{3}{*}{$\begin{array}{l}\text { At 420nm } \\
\text { AlCl }_{3} \text { yellow } \\
\text { Flavonoid } \\
\end{array}$} & & & & \\
\hline & \multirow{2}{*}{\multicolumn{2}{|c|}{ Ammonia Test }} & \multirow{2}{*}{$\mathrm{NaOH}$} & & & Phenols & Flavon & & \\
\hline & & & & & & Gallic & Rutin & Quercetin & \\
\hline $\begin{array}{l}\text { Diutinarugosa MH333102 } \\
\text { (13568) }\end{array}$ & finitely orange & +++ & ++++ & $48.9 \pm 1.2$ & $35.2 \pm 3.4$ & 0.015 & 0.001 & 0.001 & $4 \mathrm{H}+2 \mathrm{M}$ \\
\hline $\begin{array}{l}\text { Rhodotorula mucilaginosa } \\
\text { MH333100 (13564) }\end{array}$ & finitely orange & +++ & ++++ & $23.8 \pm 2.7$ & $17.4 \pm 0.6$ & 18.8 & 0.001 & 0.001 & $\mathrm{H}+5 \mathrm{~L}$ \\
\hline $\begin{array}{l}\text { R. mucilaginosa } \\
\text { MH333091 }\end{array}$ & finitely yellow & + & ++++ & $22.8 \pm 1$ & $8 \pm 0.4$ & 0.01 & 0.05 & 0.002 & $\mathrm{H}+2 \mathrm{M}+3 \mathrm{~L}$ \\
\hline $\begin{array}{l}\text { R. mucilaginosa } \\
\text { MH298827 (13567) }\end{array}$ & yellow green & ++ & ++++ & $19.3 \pm 1.1$ & $22 \pm 0.5$ & 2.6 & 0.012 & 0.005 & $4 \mathrm{H}+2 \mathrm{M}$ \\
\hline $\begin{array}{l}\text { R. mucilaginosa } \\
\text { KR264902 }\end{array}$ & finitely yellow & + & ++++ & $5.1 \pm 0.1$ & $5.9 \pm 0.1$ & 23.5 & 0.011 & 0.001 & $1 \mathrm{~L}+5 \mathrm{VL}$ \\
\hline
\end{tabular}

Table abbreviations: H: High activity $\geq 20 \mathrm{~mm}$ M: Moderate activity=19.9 to $16 \mathrm{~mm} \mathrm{~L}$ : Low activity=15.9 to $0.1 \mathrm{~mm}$

Table 3. Sequence Data of signification yeasts by molecular identification.

\begin{tabular}{|c|c|c|c|c|c|c|c|c|c|}
\hline Genus \& species & AUMMC & Source & Color & Identities & $\mathbf{S \%}$ & $\mathbf{T}$ & Closest match & Bp & GBA No \\
\hline Candida parapsilosis & 13563 & Straw berry & Creamy-white & $513 / 521$ & 98.46 & 5480 & CBS604 & 521 & MH341117 \\
\hline Diutina rugosa & 13568 & Dough & Creamy-white & $391 / 396$ & 98.73 & 5481 & ATCC10571 & 398 & МH333102 \\
\hline D. rugosa & 13571 & Guava & White & $391 / 397$ & 98.94 & 5481 & ATCC10571 & 400 & MH333095 \\
\hline D. rugosa & 13566 & Orange juice & White & $295 / 325$ & 90.79 & 5481 & CBS613 & 344 & МH341116 \\
\hline Papiliotrema laurentii & 13569 & Carrot pickled & White & $520 / 537$ & 96.83 & 5418 & ATCC18803T & 537 & MH333092 \\
\hline Rhodotorula mucilaginosa & 13562 & Molasses & Pale rose & $604 / 612$ & 98.21 & 5537 & CBS316 & 618 & MH333091 \\
\hline R. mucilaginosa & 13564 & Molasses & Rose & $608 / 618$ & 98.38 & 5537 & CBS316 & 618 & МH333100 \\
\hline R. mucilaginosa & 13567 & Molasses & Pale rose & $598 / 605$ & 98.84 & 5537 & CBS316 & 617 & MH298827 \\
\hline R. mucilaginosa & 13570 & Carrot pickled & Pale rose & $606 / 616$ & 98.53 & 5537 & CBS316 & 616 & MH341115 \\
\hline
\end{tabular}

Table abbreviations:

Genus \& species AUMMC: genus and species and Assiut University Mycological Center number

S\%: Similarity percentage T: Taxon Bp: Base pair GBA No: Gen Bank Number 


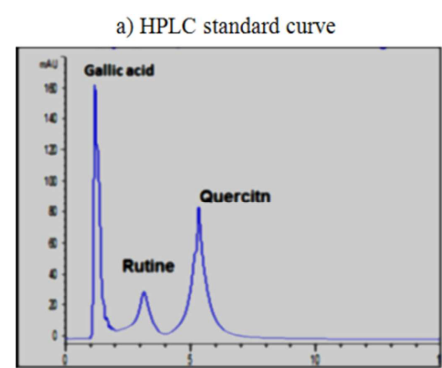

e) R. mucilaginosa MH333091
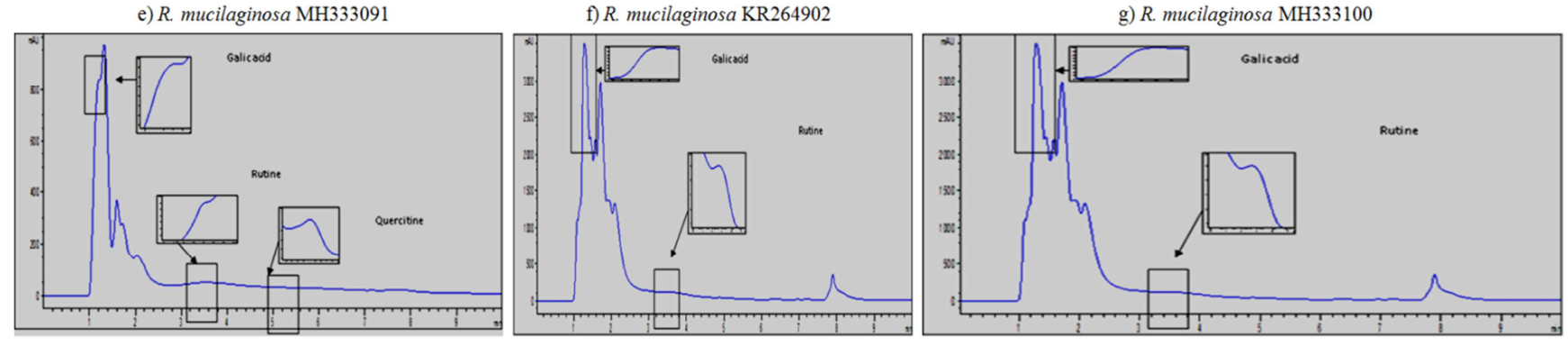

d) R. mucilaginosa $\mathrm{MH} 298827$

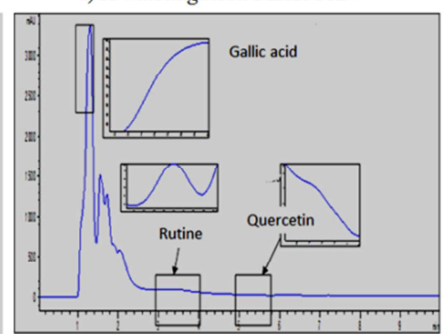

R. mucilaginosa MH333100

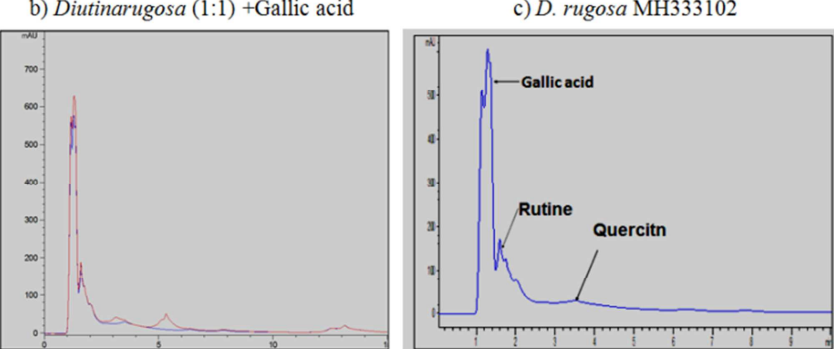

Figure 5. HPLC chromatogram for a standard mixture of gallic acid, rutin, and quercetin at $5 \mathrm{mg} / \mathrm{L}$ detected in five yeast methanolic extracts.

\subsection{Yeast Identification by Genotypic Characterization}

The molecular identification showing that the significant ten selected yeast belonged to four genera and four species three strains of Diutina rugosa, five strains of $R$. mucilaginosa, one strain of $P a$. laurentii and one strain $C$. parapsilosis. The strain scientific classification and sequence data were deposited in Gen Bank and accession numbers are given for them Table 3 \& Figure 6 .

Yeast species and genus can be isolated from sources contain a high amount of minerals, simple sugars and vitamins such as sugar cane and fruits. The yeast diversity in wine fermentations were Kluyveromyces, Saccharomyces, Candida sp., Metschnikowia, Hanseniaspora and Pichia. Thirty-three yeast isolates are isolated by using selective medium "Martin's Rose Bengal Agar (MRBA)" from 14 samples of dahl, waste juices of apple, pineapple, mango, musambi, grape, sugarcane, orange and jiggery. Many yeasts were isolated from 72 yogurt samples. Ten genus were identified: Debaryomyces hansenii, Saccharomyces cerevisiae, Hansenula sp., Mrakia frigid, Candida parapsilosis, Debaryomyces castellii, C. maltosa, Schizosaccharomyces pombe, C. mogii and Kluyveromyces marxianus. Candida and Rhodotorula were isolated and characterized from palm syrup, molasses, toddy and grapes. Six species and five genera of yeasts were isolated from the surface of Jamun fruit and identified on the basis of biochemical and morphological characters: C. ipomoeae, Candida famata, Debaryomyces hansensii, Rhodotorula mucilaginosa, C. succiphila, Pichia lachancei and Kodamaea anthophilia. Seventeen different yeast isolates were isolated from fruits mango, apple, cherry, black grapes, sapota, orange, Jamun, plum, pear, banana, figs, pomegranate, dates, green grapes, pineapple, papaya and raisins. Yeast can be identified by performing random amplified polymorphic DNA analysis for knowing the genetic interrelationship between different isolated species [27, 38-43].

\subsection{Confirmation of THE Yeast Ability to Produce Phenols and Flavonoids as Active Metabolites Flavonoids by HPLC Analysis}

Screening of the phenols and flavonoids productivity as yeast natural active metabolites in methanolic extracts were tested by used many analytical methods and Spectrophotometric analysis and includes sodium hydroxide $(\mathrm{NaOH})$, Thin Layer Chromatographic Analysis (TLC), Folin-Ciocalteau's reagent [28] Table 2.

Five selected highest phenols and flavonoids producers yeast obtained from the flowered analytical methods were confirmed by HPLC analysis with slandered gallic acid (phenols), quercetin and rutin as standard flavonoids [35, 36]. The methanolic extracts from yeasts were selected and performed by Agilent HPLC analysis, model 6890 N/5975B (Agilent Technologies, Palo Alto, CA, USA) at the analytical Chemistry Unit, ACAL, Chemistry Department, Faculty of Science, Assiut University, Assiut, Egypt.

These five selected highest flavonoid and phenol producershave the highest antibacterial effect against six pathogenic bacteria [62] Table 2.

The five highest phenols and flavonoids productive yeast methanolic extract were confirmed by HPLC analysis. According to the result, the five yeast strain have the ability of produce phenol (gallic) in quantities range between 10$23500 \mu \mathrm{g} / \mathrm{L}$ the highest strain produces phenol (gallic) is Rhodotorula mucilaginosa KR264902 which produce 23500 $\mu \mathrm{g} / \mathrm{L}$ followed by $R$. mucilaginosa MH333100 which produce $18800 \mu \mathrm{g} / \mathrm{L}$. The five yeast strain also have the ability to produce flavonoid (rutin and quercetin) in quantities range between 1-50 $\mu \mathrm{g} / \mathrm{L}$. The highest strain produce flavonoid (rutin) was $R$. mucilaginosa MH333091 and The highest strain produce flavonoid (quercetin) was $R$. mucilaginosa MH298827 Table 2 and Figure $5_{\mathrm{a}-\mathrm{g}}$. 


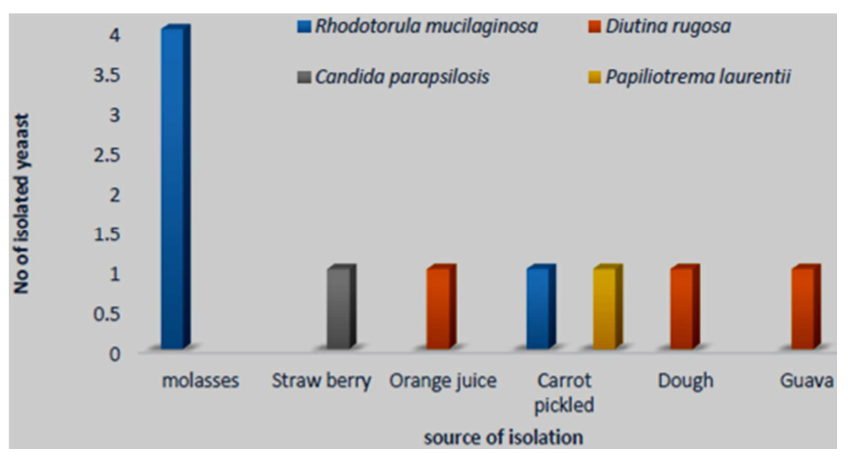

Figure 6. Identified yeast genus and species by molecular techniques.

\section{Discussion}

\subsection{Yeast Isolation}

Yeast is distributed in different food stuff. In this research, many yeasts were isolated from vegetables, fruit and other food stuff. Yeasts were isolated from some fruits and fruit products (date, grape, tomato, papaw, passion fruit, pineapple, lime, raisin, nelli, amberella, banana, plum, mango, lawulu, tangerine, papaw juice, grape-juice, pineapple-juice, nelli-juice, and mango-juice). The isolated yeast genus includes Hansensiaspora, Kloeckera, Candida, Saccharomyces, Pichia and Torulosis, but the most dominant species are Candida krusei [44].

\subsection{Yeast Identification by Genotypic Characterization}

Many Authors were identified and described by morphological characters especially the colony colors for identifications of food borne yeasts (white, off-white and red colony color and cell characters), physiological and ecological description. For example, Brettunomyces bruxellensis was isolated from (soft drink and milk), Candida mesenterica (brewery), C. parapsilosis (fruits and dairy products), Debaryomyces hansenii (preserved foods and salted meat), Kloeckera apiculate (fruits and juice), Pichia membranifaciens (fruit juice, salad, vegetable, milk \& pickles), Rhodotorula glutinis (fruit juice, cereals, vegetable and milk), R. musilaginosa (fruit juice, cereals, vegetable and milk), Saccharomyces apiculatus or Hansenia sporauvarum (fruits juice), Saccharomyces cerevisiae (fruit juice, cheese and milk). The yeast species and genus identified by a molecular technique in this investigation and also isolated from different sources and recorded by many Authors include Candida from fruits, wine, palm syrup, molasses, toddy and grapes. Candida parapsilosis isolated from different sources, it can be isolated from honey and yogurt.

Diutina rugosa was isolated from palm syrup, molasses, toddy and grapes. Rhodotorula mucilaginosa isolated from different sources, it can be also isolated from honey fruits and jams. Candida parapsilosis (100 isolates) and Rhodotorula mucilaginosa (23 isolates) are isolated from the water of a Brazilian hemodialysis center [4-7, 41-46, 61].

\subsection{Screening of Yeast Phenols and Flavonoids Active Metabolites}

Numerous studies recorded that the phenols and flavonoids were biosynthesis in yeast, this agrees with our results of the screening for phenol and flavonoid production. Numerous authors cleared that the phenols and flavonoids are biosyntheses in higher plants, algae, mushrooms, bacteria, filamentous fungi, and yeast.

Cryptococcus flavus, Rhodotorula glutamic, Saccharomyces cerevisiae and Wickerhamomyces anomalous yeasts have the ability to produce phenols and flavonoids by fermentations and the phenols content ranging between 0.2 $0.6 \mathrm{mg} / \mathrm{L}$.

Yeast is produced many kinds of phenols during wine fermentation such as catechin $10-126 \mu \mathrm{g} / \mathrm{L}$, gallic acid $11.92-53.01 \mathrm{mg} / \mathrm{kg}$, protocatechuic acid 75.12-179.03 [14, 47-49].

The chemical profile of the phenols produced by six commercial S. cerevisiae strains through the fermentation of Kiwifruit detected by HPLC studied and recorded that caffeic acid 1.1-3.0, caftaric acid 0.3-1.0, catechin 0.2-0.41, gallic acid $0.17-0.4$, chlorogenic acid 1.0, coumaric acid 0.1 , ellagic acid 0.3-1.0, epicatechin 0.8-2.0, ferulic acid 1.0-1.1, protocatechuic acid 0.14-1.0, proanthocyanidins B2 $0.21-0.5$ and total phenols $234-317 \mathrm{mg} / \mathrm{L}$. Saccharomyces cerevisiae also riches by flavonoids.

Saccharomyces cerevisiae has the ability to produce many active metabolites which act as antiaging as ascorbic acid, vitamin E, vitamin C, -tocopherol and Co-qalone. Entophytic filamentous fungi produced phenols and flavonoids.

Phenols and flavonoids were produced by fungal fermentations such as Aspergillus oryzae, A. niger. Monascus purpureus, Rhizopus oryzae, R. oligosporus produces. Also, edible mushrooms have high contents of phenols and flavonoids. Phenols were ranged between $0.40-2.21 \mathrm{mg} / \mathrm{g}$ [14, 50-57].

Natural fungal phenol and flavonoids have numerous bioactivity such as antimicrobial agents against the fungal, anti-influenza virus; anti-tuberculosis and antibacterial; antioxidant, improving the resistance of the plants; antiinflammatory; cytotoxic; anti-tumors, anti-strong pain; anticancer cell lines and anti-leukemia [54, 58-60].

\section{Conclusion}

Yeast has wide distributions almost on all surface of our foods, fruits contain high amount of minerals, vitamins, and simple sugars act as best natural sources of yeast. The yeast numbers, species and genus are affected by technique, sources of isolation and media. In the past yeast was identified biochemistry, morphologically, immunologically and physiologically results numerous yeast species and genus are confused in identification. Identification of yeast by molecular technique dissolved the problems of confusing. Yeast act as natural sources of bioactive phenols and flavonoids which have antibacterial, antioxidant and several 
activities. Yeast is promising and interesting niches for academic research as well as for industry, medicine and natural pharmacology.

\section{Acknowledgements}

I would like to thank the Analytical Chemistry Unit in Chemistry Department, Faculty of Science, Assiut University, for kind assistance in HPLC analysis.

\section{References}

[1] J. L. Legras, D. Merdinoglu, J. M. Cornuet, F. Karst. "Bread, Beer and Wine: Saccharomyces cerevisiae Diversity Reflects Human History”. Molecular Ecology. 16 (10): 2091-2102, 2007. Doi: 10.1111/j.1365-294X.2007.03266.x.PMID 17498234.

[2] M. De-Oca, R. K. Salem, A. E. Azm, H. Monroy. H. Pérez. Yeast Description, and Structure. Chapter 2. Universidad Autónomadel Estado de México, 2016.

[3] J. I. Pitt, A. D. Hocking. Fungi and Food Spoilage. Chapter 10. $2^{\text {nd }}$ Edition. Blackie Academic and Professional. London. Weinheim, New York, Tokyo, Madras. 439-468, 1997.

[4] J. A. Barnett. A History of Research on Yeasts. 8: Taxonomy. Review. Yeast. 21 (14). 1141-1193, 2004.

[5] I. A. Barnett, P. W. Payee, D. Yarrow. Yeasts: Characterization and Identification. $3^{\text {rd }}$ Edition. Cambridge University Press, Cambridge, 2000.

[6] A. Kockova-Kratochvflova, E. Slavikova, V. E. Jensen. "Numerical taxonomy of the yeast genus Debaryomyces lodder and Kreger-vanrij". Journal General Microbiology. 104. 257-268, 1978.

[7] C. P. Kurtzman, J. W. Fell. The Yeasts, A Taxonomic Study. $4^{\text {th }}$ Edition. Elsevier, Amsterdam, 1998.

[8] C. P. Kurtzman, J. Piškur. "Taxonomy and Phylogenetic Diversity Among the Yeasts". In Sunnerhagen P, Piskur J. Comparative Genomics: Using Fungi As Models. Berlin: Springer. pp. 29-46. ISBN 978-3-540-31480-6, 2006.

[9] C. P. Kurtzman, T. Boekhout, V. Robert, J. W. Fell. Methods To Identify Yeasts. Yeasts in Food. Boekhout T, Robert V, Eds. CRC Press, Germany. 69-121, 2003.

[10] C. P. Kurtzman, J. W. Fell, T. Boekhout. The Yeasts a Taxonomic Study. $15^{\text {th }}$ Edition. Elsevier, 2011.

[11] M. Percival. Antioxidants. Clinical Nutrition Insight. 31. 1-4, 1998.

[12] M. S. Stankovic, M. Zia-Ui-Haq, B. M. Bojovic, M. D. Topuzovic. "Total Phenols, Flavonoid Content and Antioxidant Power of Leaf, Flower and Fruits from Cornelian cherry (Corn usmas L.)". Bulgarian Journal of Agricultural Science. 20 (2). 132-137, 2014.

[13] J. Mierziak, K. Kostyn, A. Kulma. "Flavonoids As Important Molecules of Plant Interactions With The Environment". Review. Molecules. 19 (10). 16240-16265, 2014. DOI: 103390/molecules 191016240.

[14] N. T. Huynh, J. V. Camp, K. Smagghe, G. Raes. "Improved
Release and Metabolism of Flavonoids by Steered Fermentation Processes": A Review. International Journal of Molecular Sciences. 15 (11). 19369-19388, 2014. Doi: 10.3390/ijms151119369.

[15] M. Pinelo, J. Sineiro, M. J. Nunez. "Mass Transfer During Continuous Solid-Liquid Extraction of Antioxidants From Grape by Products". Journal of Food Engineering. 77 (1). 5763, 2006.

[16] A. Cerda, M. E. Martínez, C. Soto, P. Poirrier, J. R. PerezCorrea, J. R. Vergara-Salinas, M. E. Zúñiga. "The Enhancement of Antioxidant Compounds Extracted From Thymus vulgaris Using Enzymes and The Effect of Extracting Solvent”. Food Chemistry. 139 (4). 138-143, 2013.

[17] R. K. Yadav, P. Kalia, R. Kumar, V. Jain. "Antioxidant and nutritional activity studies of green leafy vegetables". International Journal of Food Science and Technology. 4. 707$712,2013$.

[18] C. Martin, E. Butelli, K. Petroni, C. Tonelli. "How can research on plants contribute to promoting human health (OA)". Plant Cell. 23 (5), 2011. 1685-1699. 10. 1056/NEJM198701293160502.

[19] K. B. Raper, D. I. Fennell. The genus Aspergillus. Williams \& Wilkins, Baltimore, USA. 1-868, 1965.

[20] R. A. Samson, E. S. Hoekstra, J. C. Frisvad, O. Fittenborg. Introduction to foodborne fungi. $4^{\text {th }}$ Edition. Printed by Ponsen and Looyen, Wageningen, Netherland. pp. 222-231, 1995.

[21] C. P. Kurtzman, J. W. Fell. “The Yeast Handbook”, P. Gábor, C. L. de la Rosa, Editions. Biodiversity and Ecophysiology of Yeasts". Berlin: Springer. Pp. 11-30. ISBN 978-3-540-26100$1,2005$.

[22] C. P. Kurtzman, J. W. Fell. Yeast Systematic and Phylogeny. Implications of Molecular Identification Methods For Studies in Ecology. Biodiversity and Ecophysiology of Yeasts. The Yeast Handbook. Springer, 2006.

[23] L. J. Wickerham. Taxonomy of yeasts. Technical Bulletin of the US Department of Agriculture. 1029: 1-55, 1951.

[24] S. Lallianrawna, R. Muthukumaran, V. Ralte, G. Gurusubramanian, N. S. Kumar. "Determination of Total Phenolic Content, Total Flavonoid Content And Total Antioxidant Capacity of Ageratina adenophora (Spreng.) King \& H. Rob”. Science Vision. 13 (4). 149-156, 2013.

[25] G. C. Bag, P. G. Devi. “Assessment of Total Flavonoid Content and Antioxidant Activity of Methanolic Rhizome Extract of Three Hedychiums pecies of Manipur Valley". International Journal of Pharmaceutical Sciences Review and Research. 30 (1). 154-159, 2015. ISSN 0976-044X.

[26] T. R. Johanson, C. L. Caes. Laboratory Experiments In Microbiology. 9th Edition, San Francisco, USA. pp. 470, 2010.

[27] S. Chatterjee, B. Ghosh, R. Ray. "Isolation And Characterization of Local Yeast Strains From Waste Fruit Juices, From Jaggery and Dahi samples". International Journal of Chemical Sciences. 9 (2). 647-656, 2011.

[28] M. M. Eman, I. S. Khallaf, S. M. Nassar. "Screening Of The Yeast Phenols And Flavonoids By Many Analytical Methods". (In press) 2019. 
[29] C. S. Vimalkumar, C. S. Vimalkumar, V. B. Hosagaudar, S. R. Suja, V. Vilash, N. M. Krishnakumar, P. G. Latha. "Comparative Preliminary Phytochemical Analysis of Ethanolic Extracts of Leaves of Olea dioica Roxb, infected with the rust fungus Zaghouaniaoleae (EJ Butler) Cummins and Non Infected Plants". Journal of Pharmacognosy and Phytochemistry. 3 (4). 69-72, 2014.

[30] R. A. Lewis, K. F. Austen. "The Biologically Active Leukotrienes: Biosynthesis, Metabolism, Receptors, Functions and Pharmacology". Journal of Clinical Investigation. 73 (4). 889-897, 1984.

[31] D. A. Lewis. Anti-inflammatory Drugs From Plant and Marine Sources. Birkhauser Verlag, Basel, Switzerland. 27. 3373, 1989.

[32] A. A. Ordonez, J. D. Gomez, M. Vattuone, M. I. lsla. "Antioxidant Activities of Sechiumedule (Jacq.) Swart Extracts". Food Chemistry. 97 (3). 452-458, 2006. DOI: 10.1016/j.foodchem.2005.05.024.

[33] Y. A. Yahaya, M. M. Don. "Flavonoid Production by $T$. lactinea, Screening of Culture Conditions Via OFAT and Optimization Using Response Surface Methodology (RSM)". Journal of the Korean Society for Applied Biological Chemistry. 57 (6). 749-757, 2014. DOI 10.1007/s13765-0144246-2.

[34] Y. Lim, T. Lim, J. Tee. "Antioxidant Properties of Several Tropical Fruits: A Comparative Study". Food Chemistry. 103 (3). 1003-1008, 2007. http://dx.doi.org.

[35] K. A. Lombard, E. Geoffriau, E. Peffley. "Flavonoid Quantification In Onion By Spectrophotometric And HighPerformance Liquid Chromatography Analysis". Hort Science. 37 (4). 682-685, 2002.

[36] M. S. Stankovic. "Total Phenolic Content, Flavonoid Concentration And Antioxidant Activity of Marrubium peregrinum L extracts". Kragujevac Journal Science. 33. 63$72,2011$.

[37] C. P. Kurtzman. "Molecular taxonomy of the yeasts". Yeast. $10 \quad$ (13). 1727-1740, 1994. DOI: 10.1002/yea.320101306.PMID7747515.

[38] J. F. Spencer, D. M. Spencer. "Yeasts In Natural And Artificial Habitats". Springer-Verlag. Berlin- Heidelberg, 1997.

[39] D. A. Mills, E. A. Johannsen, L. Cocolin. "Yeast Diversity And Persistence In Botrytis-affected Wine Fermentations". Applied and Environmental Microbiology. 68 (10). 48844893, 2002.

[40] S. R. Moreira, R. F. Schwan, E. P. De-Carvalho, A. E. Wheals. "Isolation And Identification Of Yeasts And Filamentous Fungi From Yoghurts In Brazil". Brazilian Journal of Microbiology. 32 (2). 117-122, 2001.

[41] S. K. Ghosh, K. R. Samadder. "Characterization And Biomass Production Potential Of Yeast Flora Of Some Natural Sources Of Kalyani”. Journal of Mycopathological Research. 29 (2). 111-117, 1991.

[42] S. K. Ghosh. "Study Of Yeast Flora From The Fruit Of Syzygium cumini (Linn) Skeel". Agricultural and Biological Journal of North America. 2 (8). 1166-1170, 2011.

[43] P. K. Lathar, A. Sharma, I. Thaku. "Isolation And Random Amplified Polymorphic DNA (RAPD) Analysis of Wild Yeast
Species From 17 Different Fruits". Journal of Yeast and Fungal Research. 1 (8). 146-151, 2010.

[44] D. Warnasuriya, A. W. Liyanage, G. G. Weera wansa, P. K. Athauda, P. M. Jayatissa. "Isolation and Characterization of Yeasts Of Some Fruits And Fruit Products of Srilanka". Journal of the National Science Foundation of Srilanka. 13 (1). $71-75,1985$.

[45] C. R. Arias, J. K. Burns, L. M. Friedrich, R. M. Goodrich, M. E. Parish. "Yeast Species Associated With Orange Juice: Evaluation of Different Identification Methods". Applied and Environmental Microbiology. 68 (4). 1955-1961, 2002.

[46] C. M. Carvalho, S. Meirinho, L. M. Estevinho, A. Choupina. "Yeast Species Associated With Honey: Different Identification Methods". Archivos de Zootecnia. 59 (225). 103-113, 2010.

[47] S. Coghe, K. Benoot, F. V. Delvaux, B. Erhaegen, FR Delvaux. "Ferulic Acid Release And 4-vinyl Guaiacol Formation During Brewing And Fermentation: Indications For Feruloyl Esterase Activity In Saccharomyces cerevisiae". Journal of Agricultural and Food Chemistry. 52 (3). 602-608, 2004.

[48] J. Moore, Z. Cheng, J. Hao, G. Guo, J. G. Liu, C. Lin, L. Yu. "Effects Of Solid-State Yeast Treatment On The Antioxidant Properties, Protein And Fiber Compositions of Common Hard Wheat Bran". Journal of Agricultural and Food Chemistry. 55 (25). 10173-10182, 2007.

[49] Akalın H, Bayram M, Anlı RE. Determination of Some Individual Phenolic Compounds And Antioxidant Capacity Of Mead Produced From Different Types of Honey. Journal of the Institute of Brewing. 123 (1). 167-174, 2017. DOI 10.1002/jib.396.

[50] X. Li, Y. Xing, L. Cao, Q. Xu, S. Li, R. Wang, Z. Jiang, Z. Che, H. Lin. "Effects Of Six Commercial Saccharomyces cerevisiae Strains On Phenolic Attributes, Antioxidant Activity And Aroma Of Kiwifruit (Actinidia deliciosa cv.) wine. Research Article. BioMed Research International. 1-10, 2017. DOI. org/10.1155/2017/2934743.

[51] F. Du, F. Zhang, F. Chen, A. Wang, Q. Wang, X. Yin, Wang S. "Advances In The Microbial Heterologous Production of Flavonoids". African Journal Microbiology Research. 5 (18). 2566-2574, 2011.

[52] S. Kumar, A. K. Pandey. "Chemistry and Biological activities of Flavonoids: An Overview". Review Article. Scientific World Journal. 1-16, 2013. ID. 162750.

[53] I. S. Bartosz, G. Bartosz. "Effect Of Antioxidants Supplementation On Aging And Longevity". BioMed Research International. Review Article. (3). 1-17, 2014. DOI: org/10.1155/2014/404680.

[54] P. N. De-Carvalho, E. O. Silva, D. A Chagas-Paula, J. H. Luiz, M. Ikegaki. "Importance And Implications Of The Production Of Phenolic Secondary Metabolites By Endophytic Fungi”. A Mini-Review. Medicinal Chemistry. 16 (4). 259-271, 2016.

[55] K. Gezer, M. E. Duru, I. Kivrak, A. Turkoglu, N. Mercan, H. Turkoglu, S. Gulcan. "Free Radical Scavenging Capacity And Antimicrobial Of Wild Mushrooms From Turkey". African Journal of Biotechnology. 5 (20). 1924-1928, 2006.

[56] I. C. Ferreira, L. Barros, R. M. Abreu. "Antioxidants In Wild Mushrooms". Article Literature Review. Current Medicinal Chemistry. 16 (12). 1543-1560, 2009. 
[57] A. N. Rashidi, T. A. Yang. "Nutritional and Antioxidant Values of Oyster Mushroom (P. sajor-caju) Cultivated on Rubber Sawdust". International Journal on Advanced Science Engineering and Information Technology. 6 (2). 161-164, 2016.

[58] M. M. Cowan. Plant Products As Antimicrobial Agents. Clinical Microbiology Reviews. 12 (4). 564-582, 1999.

[59] J. P. Rauha, S. Remes, M. Heinonen, A. Hopia, M. T. KähkönenKujala, K. Pihlaja, H. Vuorela, P. Vuorela. "Antimicrobial Effects of Finnish Plant Extracts Containing Flavonoids And Other Phenolic Compounds". International Journal of Food Microbiology. 56 (1). 3-12, 2000. www.elsevier.nl/locate/ijfood micro.
[60] P. Romano, C. Fiore, M. Paraggio, M. Caruso, A. Capece. "Function of Yeast Species And Strains In Wine Flavor". International Journal Food Microbiology. 86. 169-180, 2003.

[61] L. B. Montanari, F. G. Sartori, D. B. Ribeiro, L. F. Leandro, R. H. Pires, M. S. Melhem, C. A. De-Mello, C. H. Martins. "Yeast Isolation and Identification in Water Used In A Brazilian Hemodialysis Unit By Classic Microbiological Techniques And Raman spectroscopy". Journal Water and Health. 16 (2). 334-337, 2018.

[62] M. M. Eman, I. S. Khallaf, S. M. Nassar. "Antibacterial Activities of Some Yeast Strains and GC/MS Analysis of Rhodotorula mucilaginosa AUMC13565 Bioactive Metabolites". Assiut University Journal of Botany and Microbiology 47 (2): 55-70, 2018. 